\title{
Article \\ Nanomaterial Synthesis in Ionic Liquids and Their Use on the Photocatalytic Degradation of Emerging Pollutants
}

\author{
Raquel Corchero ${ }^{1}$, Rosario Rodil ${ }^{2}\left(\mathbb{D}\right.$, Ana Soto $^{1}\left(\mathbb{D}\right.$ and Eva Rodil ${ }^{1, *(1)}$ \\ 1 CRETUS Institute, Department of Chemical Engineering, Universidade de Santiago, \\ E-15782 Santiago de Compostela, Spain; raquel.corchero@rai.usc.es (R.C.); ana.soto@usc.es (A.S.) \\ 2 Department of Analytical Chemistry, Nutrition and Food Science, Universidade de Santiago de Compostela, \\ E-15782 Santiago de Compostela, Spain; rosario.rodil@usc.es \\ * Correspondence: eva.rodil@usc.es
}

check for updates

Citation: Corchero, R.; Rodil, R.; Soto, A.; Rodil, E. Nanomaterial Synthesis in Ionic Liquids and Their Use on the Photocatalytic

Degradation of Emerging Pollutants. Nanomaterials 2021, 11, 411. https:// doi.org/10.3390/nano11020411

Academic Editor: Vincenzo Vaiano

Received: 17 January 2021

Accepted: 2 February 2021

Published: 5 February 2021

Publisher's Note: MDPI stays neutral with regard to jurisdictional claims in published maps and institutional affiliations.

Copyright: (C) 2021 by the authors. Licensee MDPI, Basel, Switzerland. This article is an open access article distributed under the terms and conditions of the Creative Commons Attribution (CC BY) license (https:/ / creativecommons.org/licenses/by/ $4.0 /)$.

\begin{abstract}
The unique properties of ionic liquids make them suitable candidates to prepare nanoscale materials. A simple method that uses exclusively a corresponding bulk material and an ionic liquid-in this case, $\left[\mathrm{P}_{6,6,6,14}\right] \mathrm{Cl}$ - was used to prepare $\mathrm{AgCl}$ nanoparticles and $\mathrm{AgCl} @ \mathrm{Fe}_{3} \mathrm{O}_{4}$ or $\mathrm{TiO}_{2} @ \mathrm{Fe}_{3} \mathrm{O}_{4}$ magnetic nanocomposites. The prepared nanomaterials were characterized by X-ray powder diffraction, scanning electron microscopy, transmission electron microscopy, ultravioletvisible spectroscopy, and X-ray photoelectron spectroscopy. The photodegradation of atenolol as a model pharmaceutical pollutant in wastewater was investigated under ultraviolet-visible light irradiation using the different synthesized nanocatalysts. In the presence of $0.75 \mathrm{~g} \cdot \mathrm{L}^{-1} \mathrm{AgCl}$ nanoparticles, a practically complete degradation of $10 \mathrm{ppm}$ of atenolol was obtained after $30 \mathrm{~min}$, following pseudo-first-order reaction kinetics. The effect of different variables (concentrations, $\mathrm{pH}$, oxidant agents, etc.) was analyzed. The recyclability of the nanocatalyst was tested and found to be successful. A degradation mechanism was also proposed. In order to improve the recovery stage of the nanocatalyst, the use of magnetic nanocomposites is proposed. Under the same experimental conditions, a slightly lower and slower degradation was achieved with an easier separation. The main conclusions of the paper are the suitability of the use of ionic liquids to prepare different nanocatalysts and the effectiveness of these at degrading an emerging pollutant in wastewater treatment.
\end{abstract}

Keywords: ionic liquids; nanocatalyst; atenolol; kinetics; degradation pathways

\section{Introduction}

Effluents containing emerging pollutants, specifically pharmaceuticals and personal care products (PPCPs) (ibuprofen, atenolol, carbamazepine, etc.), can be detrimental to nature and health [1-3]. Different entry paths of these compounds into the environment are known, among which urban wastewater and hospital effluents are considered the most significant [2,4]. Traditional wastewater treatment plants are not designed to remove them [4-8]. This concerns scientific and environmental agencies as these compounds are reaching rivers and canals. Gavrilescu et al. reported the concentration of these compounds in rivers around the world. In particular, European rivers have on average $14-44 \mathrm{ng} \cdot \mathrm{L}^{-1}$ of ibuprofen, $314 \mathrm{ng} \cdot \mathrm{L}^{-1}$ of atenolol, and $9-157 \mathrm{ng} \cdot \mathrm{L}^{-1}$ of carbamazepine, among others [9].

These facts have aroused great interest in investigating wastewater treatment techniques that remove or degrade PPCPs, including filtration [10,11], adsorption [12,13], coagulation/flocculation [14], biological processes [15,16], and degradation by various advanced oxidation processes (AOPs) such as photo-Fenton $[17,18]$, ozonation $[19,20]$, ultrasound treatment [21], electrochemical oxidation [22,23], ultraviolet (UV)/ $\mathrm{H}_{2} \mathrm{O}_{2}$ [24,25], etc. Among the AOPs, degradation using ultraviolet-visible (UV-Vis) irradiation and nanomaterials as photocatalytic agents must be highlighted due to the promising results obtained up to now [26-31]. Advantages of this method include application at low temperatures and ambient pressures, low environmental impact, easy mineralization of contaminants, 
and low operating costs [32]. In this research line, Hapeshi et al. [28] studied the degradation by UV irradiation of ofloxacin and atenolol with $\mathrm{TiO}_{2}$ nanoparticles as catalysts. Martinez et al. [29] researched degradation of carbamazepine using P-25, anatase, rutile, $\mathrm{ZnO}$, and multi-walled carbon nanotubes-anatase composites as catalysts. The load and type of catalyst and the effect of adding $\mathrm{O}_{2}$ or $\mathrm{H}_{2} \mathrm{O}_{2}$ were also analyzed by these authors. Karunakaran et al. [30] removed carboxylic acids from water using UV irradiation with $\mathrm{Al}_{2} \mathrm{O}_{3}$ and $\mathrm{SiO}_{2}$ nanoparticles. Ji et al. [31] studied the degradation of atenolol in aqueous $\mathrm{TiO}_{2}$ suspensions using a high-pressure mercury lamp as a source of radiation.

The number of possible nanocatalysts for degradation of PPCPs is high, and their synthesis methods varied [33,34]. However, the main drawback in the use of nanomaterials in wastewater treatment is the separation step, owing to the high operation costs. To solve this issue, magnetic nanoparticles or nanocomposites are being proposed $[35,36]$. Iron oxide and titanium oxide [37,38], $\mathrm{ZnO} / \mathrm{AgI} / \mathrm{Fe}_{3} \mathrm{O}_{4}$ nanocomposite [39], or $\mathrm{FeO}$ and $\mathrm{ZnO}[40]$ were easily separated and re-used without losing their photocatalytic activity in different applications.

In recent years, ionic liquids (ILs) have been shown as task-specific solvents of great interest in the preparation of different nano-scale materials [41-46]. $\mathrm{AgCl}$ [47], $\mathrm{Ag}$ [48], $\mathrm{TiO}_{2}$ [49], and $\mathrm{CeO}_{2}$ [50], among other nanoparticles, have been successfully synthesized using these neoteric solvents. Even though the preparation methods are different, all of them share the advantages of ILs, mainly their green character (atmospheric contamination is avoided with the use of these salts) and their tunable character. Chen et al. [51] used a solvothermal process to synthesize the photocatalyst bismuth phosphate $\left(\mathrm{BiPO}_{4}\right)$ with different morphologies in the presence of the ionic liquid $[\mathrm{Omim}] \mathrm{H}_{2} \mathrm{PO}_{4}$. Its photocatalytic performance was tested under ultraviolet irradiation for the elimination of ciprofloxacin as a target contaminant. Xia et al. [52], using the same method, synthesized the g- $\mathrm{C}_{3} \mathrm{~N}_{4} / \mathrm{BiPO}_{4}$ hybrid material and tested it as a photocatalyst for the removal of methylene blue dye and the antibiotic ciprofloxacin. The photocatalytic degradation of rhodamine B, tetracycline hydrochloride, ciprofloxacin, and bisphenol A was carried out using carbon quantum dotmodified bismuth oxychloride/bismuth oxybromide nanosheet by $\mathrm{Hu}$ et al. [53]. To that end, an in situ ionic liquid-induced strategy was used with $\left[\mathrm{C}_{16} \mathrm{mim}\right] \mathrm{Cl}$. Using the same $\mathrm{IL}$, Yin et al. [54] synthesized novel carbon quantum dot-modified $\mathrm{PbBiO}_{2} \mathrm{Cl}$ for degradation of tetracycline hydrochloride, ciprofloxacin, and bisphenol $\mathrm{A}$. BiOBr microspheres were synthesized [55] in the presence of three different reactive ILs, namely 1-butyl-3vinylimidazolium bromide, poly(1-butyl-3-vinylimidazolium) bromide, and poly(1-butyl3-vinylimidazolium bromide acrylamide. Photocatalytic activity of the microspheres was tested with rodamine B and tetracycline. All these nanocatalysts [51-55] have shown good results in the degradation of pharmaceuticals; however, their synthesis is complicated and requires different solvents besides the IL.

In this work, $\mathrm{AgCl}$ nanoparticles and magnetic nanocomposites $\left(\mathrm{AgCl} @ \mathrm{Fe}_{3} \mathrm{O}_{4}\right.$ and $\left.\mathrm{TiO}_{2} @ \mathrm{Fe}_{3} \mathrm{O}_{4}\right)$ are prepared using the IL trihexyl(tetradecyl)phosphonium chloride $\left(\left[\mathrm{P}_{6,6,6,14}\right]\right.$ $\mathrm{Cl})$ and the corresponding bulk materials. The selected method of preparation $[47,56]$ is quick and easy. The synthesized nanomaterials are characterized by $\mathrm{X}$-ray powder diffraction (XRD), transmission electron microscopy (TEM), scanning electron microscopy (SEM), ultraviolet-visible spectroscopy (UV-Vis), and X-ray photoelectron spectroscopy (XPS). Atenolol (ATL) is used as a pharmaceutical pollutant model, and $\mathrm{AgCl}$ nanoparticles are used as catalysts in its photodegradation with UV light. Several parameters are evaluated: nanocatalyst loading, atenolol concentration, addition of oxidant agents, and $\mathrm{pH}$. The kinetics of the degradation process are determined by measuring the variation of the ATL concentration with time using high-performance liquid chromatography (HPLC), and the degradation products are identified. Furthermore, recyclability of the nanocatalyst is shown. Finally, the synthesized magnetic nanocomposites, prepared with the aim of facilitating catalyst recovery, are also tested under the same conditions as the individual nanoparticles. 


\section{Materials and Methods}

\subsection{Materials}

ATL (>98\%), whose structure is shown in Figure 1, magnetite (97\%, nanopowder 50-100 nm), titanium (IV) oxide (>99.5\% P25 degussa, nanopowder), silver chloride $(99 \%)$, toluene ( $\geq 99.5 \%)$, sulfuric acid $(72 \%)$, acetic acid $(99 \%)$, hydrogen peroxide (30\% in $\left.\mathrm{H}_{2} \mathrm{O}\right)$, acetone $(\geq 99.5 \%)$, and ammonia (25\%) were obtained from Merck / Sigma-Aldrich (Germany). Ethanol (99.8\%) and sodium hydroxide were purchased from Panreac, and methanol (99.9\%, HPLC) was supplied by Scharlau (Barcelona, España). $\left[\mathrm{P}_{6,6,6,14}\right] \mathrm{Cl}$, was obtained from CYTEC industries (Woodland Park, New Jersey, United States) under the trade name CYPHOS IL 101 (97.7\%); Figure 2. The IL was dried at $70{ }^{\circ} \mathrm{C}$ under high vacuum (absolute pressure $<1 \mathrm{~Pa}$ ) for $24 \mathrm{~h}$ and then stored under inert atmosphere. The water content $(<2000$ ppm) was measured by titration using a Metrohm 737 Karl Fischer coulometer. IL final purity was checked by ${ }^{1} \mathrm{H}$ and ${ }^{13} \mathrm{C}$ NMR analyses (Figure S1).<smiles>CC(C)NCC(O)COc1ccc(CC(N)=O)cc1</smiles>

Figure 1. Structure of atenolol (ATL).

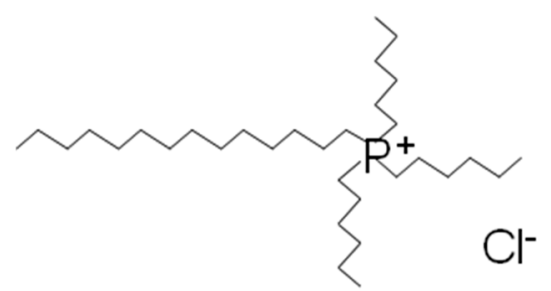

Figure 2. Structure of $\left[\mathrm{P}_{6,6,6,14}\right] \mathrm{Cl}$.

\subsection{Preparation of AgCl Nanoparticles}

$\mathrm{AgCl}$ nanoparticles were synthesized using a previously published method [56]. In a round-bottom flask, a certain amount of bulk $\mathrm{AgCl}$ was mixed with $\left[\mathrm{P}_{6,6,6,14}\right] \mathrm{Cl}$ to obtain a concentration of $10 \% \mathrm{w} / \mathrm{w}$. The mixture was stirred vigorously at $120^{\circ} \mathrm{C}$ for $4 \mathrm{~h}$. Then, ethanol was used to precipitate the nanoparticles. They were washed three times with acetone to remove any possible trace of IL. Finally, the nanoparticles were dried at $80{ }^{\circ} \mathrm{C}$ for $12 \mathrm{~h}$ in the dark.

\subsection{Preparation of $\mathrm{AgCl} @ \mathrm{Fe}_{3} \mathrm{O}_{4}$ and $\mathrm{TiO}_{2} @ \mathrm{Fe}_{3} \mathrm{O}_{4}$ Magnetic Nanocomposites}

The procedure above mentioned [56] was used, for the first time, to synthesize nanocomposites $\left(\mathrm{AgCl} @ \mathrm{Fe}_{3} \mathrm{O}_{4}\right.$ and $\left.\mathrm{TiO}_{2} @ \mathrm{Fe}_{3} \mathrm{O}_{4}\right)$. Commercial magnetic nanoparticles of $\mathrm{Fe}_{3} \mathrm{O}_{4}$ were dissolved in pure $\left[\mathrm{P}_{6,6,6,14}\right] \mathrm{Cl}$ to obtain a $5 \% w / w$ concentration. When a homogeneous solution was obtained, the chosen photocatalytic nanomaterial (synthesized $\mathrm{AgCl}$ or commercial $\mathrm{TiO}_{2}$ nanoparticles) was added at a $5 \% w / w$ concentration. The mixture was stirred at $120{ }^{\circ} \mathrm{C}$ for $4 \mathrm{~h}$. Precipitation and washing procedures were performed as described above.

\subsection{Characterization of the Nanomaterials}

The prepared nanomaterials were structurally characterized by XRD. The diffraction patterns were obtained using an X-ray Philips powder diffractometer (PW 1710) with a Cu-k $\alpha$ X-ray source $(\lambda=1.54 \AA)$. SEM and TEM were used to determine the shape and size of the nanomaterials. One drop of dispersed nanoparticles in toluene was deposited on a 400 mesh carbon formvar grid and allowed to evaporate at room temperature. SEM images 
were obtained with a field emission scanning electron microscope Zeiss Ultra Plus FESEM, with energy-dispersive $X$-ray micro-analysis (EDS). TEM images were obtained using a Philips CM-12 microscope (FEI Company, Eidhoven, The Netherlands) with a MegaView docu-II camera and IMAX image analysis Software SIS NT. The UV-Vis absorption spectra of nanoparticles dispersed in toluene were obtained with an Agilent 8543 absorption spectrophotometer. Finally, to confirm the surface composition and chemical states of the nanocatalysts before and after usage, a Thermo Scientific K-Alpha ESCA instrument equipped with an aluminum $\mathrm{K} \alpha$ monochromatized radiation at $1486.6 \mathrm{eV} X$-ray source (XPS) was used.

\subsection{Experimental Set-Up for Photocatalytic Degradation of ATL}

The photocatalytic performance of the obtained nanomaterials was evaluated by degrading 10 ppm ATL stock solutions. The experiments were carried out in a 250-mL designed glass photoreactor (Figure 3) equipped with a low-pressure mercury vapor lamp (UV-C, $\lambda=280-100 \mathrm{~nm}$ ). Furthermore, the reactor was equipped with a double stirring system consisting of a magnetic stirrer and a gas diffuser. The reaction camera including the irradiation source was surrounded by a quartz cooling jacket to control the temperature.
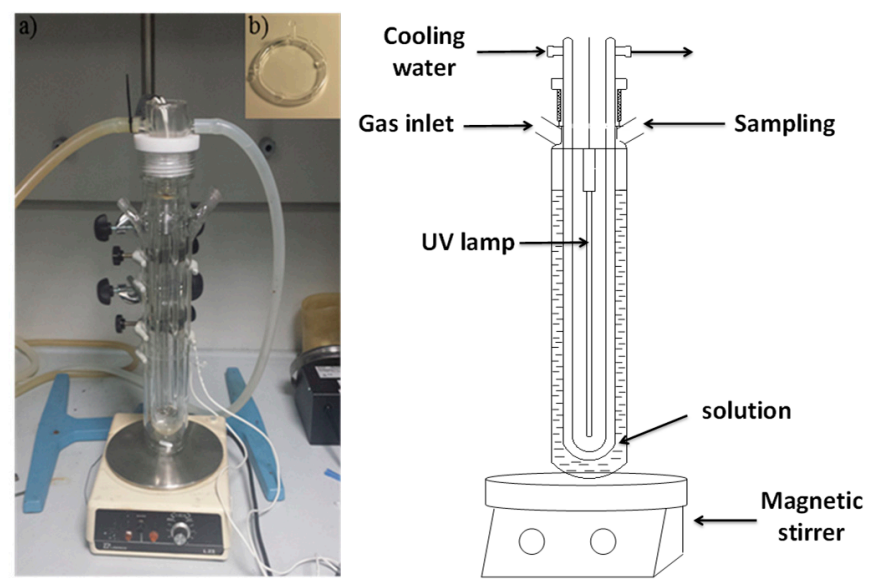

Figure 3. Glass photoreactor picture and scheme.

The nanomaterial, dispersed in water solution, was added to the ATL stock solution to obtain a concentration of $0.75 \mathrm{~g} \cdot \mathrm{L}^{-1}$ (except when this effect was evaluated where the corresponding concentrations were prepared). Before starting irradiation, the suspension was magnetically and bubble-stirred for $30 \mathrm{~min}$ in the dark to achieve adsorption-desorption equilibrium. Then, the UV light was switched on and samples were taken at different time intervals during the reaction, centrifuged (14,500 rpm during $10 \mathrm{~min}$ ), and immediately analyzed. In the experiments carried out, helium was bubbled in to maintain an inert atmosphere free of oxidizing agents (except when the effect of oxidizing agents was evaluated). All tests were accomplished at least twice, guaranteeing their repeatability.

\subsection{Analytical Method}

The ATL concentration was measured by high-performance liquid chromatography (HPLC) using an Agilent 1100 chromatograph equipped with a diode array detector $(\lambda=224 \mathrm{~nm})$, vacuum degasser unit, quaternary pump, and thermostated autosampler. Separation was performed by a ZORBAZ SB-C18 column $(4.6 \times 150 \mathrm{~mm}$; $80 \AA$ pore size $)$ at $30{ }^{\circ} \mathrm{C}$. The isocratic elution was $20 / 80(v / v)$ methanol/ammonium acetate $10 \mathrm{mM}$ (aq.). Flow rate was set as $0.5 \mathrm{~mL} / \mathrm{min}$ and the injection volume was $20 \mu \mathrm{L}$. 
ATL concentration was determined using an area-concentration calibration. Subsequently, the concentration of the samples was measured, and the degradation percentage was calculated according to Equation (1):

$$
\text { \%degradation }=\left(1-\frac{C}{C_{0}}\right) \cdot 100
$$

where $C_{0}$ and $C$ are the initial and the sample concentration of ATL, respectively.

Furthermore, the degradation products were identified by liquid chromatographyquadrupole-time-of-flight (LC-Q-TOF). To that end, an Agilent 1200 Series HLPC system consisting of a membrane degasser, a binary high-pressure gradient pump, an autosampler, and a thermostated LC column compartment was used. This system was interfaced to a Q-TOF mass spectrometry (Q-TOF-MS) instrument (Agilent 6520 Series) equipped with a dual electrospray ion source. Separation was carried out on a $100 \times 2 \mathrm{~mm}$ (particle size: 3 $\mu \mathrm{m}$ ) Synergi Fusion RP (Phenomenex, Torrance, CA, USA) at a flow rate of $0.2 \mathrm{~mL} \mathrm{~min}^{-1}$ and temperature of $35{ }^{\circ} \mathrm{C}$. Mobile phase consisted of Milli-Q water (A) and methanol (B), both containing $5 \mathrm{mM}$ of ammonium acetate. The gradient was as follows: $0 \mathrm{~min}$, $5 \% \mathrm{~B} ; 10-12 \mathrm{~min}, 100 \% \mathrm{~B} ; 12.10-25 \mathrm{~min}, 5 \% \mathrm{~B}$. For the Q-TOF-MS, nitrogen (99.9\%), used for nebulizing and drying gas, was provided by a nitrogen generator (Erre Due Srl, Livorno, Italy). Nitrogen (99.9995\%) used for collision-induced dissociation was supplied by Praxair Spain (A Coruña, Spain). The electrospray ion source was operated in positive (no transformations products were detected in negative) mode with the following parameters applied: gas temperature: $350{ }^{\circ} \mathrm{C}$; drying gas: $7 \mathrm{~L} \mathrm{~min}^{-1}$; nebulizer: 42 psig; capillary: $4000 \mathrm{~V}$; fragmentor: $120 \mathrm{~V}$; skimmer voltage: $65 \mathrm{~V}$; octopole radio frequency peak: $750 \mathrm{~V}$. The instrument was operated in the $2 \mathrm{GHz}$ (extended-dynamic range) mode, which provides a Full Width at Half Maximum (FWHM) resolution of ca. 4500 at m/z 121 and ca. 11,000 at $922 \mathrm{~m} / \mathrm{z}$. A reference solution was also continuously infused using a second nebulizer of the dual electrospray ion source $(5 \mathrm{psig})$ to recalibrate the Q-TOF using two masses (m/z 121.0509 and 922.0098) and maintain mass accuracy. Instrument control, data acquisition, and evaluation were performed with the MassHunter software (Agilent Technologies). Finally, MS/MS analyses were performed using different collision energies $(10,20$, and $40 \mathrm{~V})$ and interpreted in order to tentatively elucidate the structure of the degradation products.

\section{Results and Discussion}

\subsection{Characterization of $\mathrm{AgCl}$ Nanoparticles}

The morphology of the $\mathrm{AgCl}$ nanoparticles was characterized by SEM and TEM (Figure 4a,b). As shown in Figure 4a, the dispersed $\mathrm{AgCl}$ nanoparticles have a regular and spherical shape with homogeneous distribution (5-20nm). Figure $4 \mathrm{~b}$ shows the SEM image of the precipitated nanoparticles; the solid was formed of large cubic agglomerates, behavior which has previously been reported by other authors $[47,57,58]$. The UV-Vis absorption spectrum of the dispersed nanoparticles (Figure S2) indicates the presence of silver chloride, with a characteristic absorption peak below $300 \mathrm{~nm}$ [59]. Moreover, there are no absorption peaks in the visible light region, which indicates that the photosensitive silver chloride has not been converted into silver (its absorption peak should appear at $400 \mathrm{~nm}$ [60]). AgCl nanoparticles were structurally characterized by XRD. The position and relative intensities of the peaks observed in Figure S3 indicate the presence of chlorargyrite only, the cubic structure of silver chloride, with the peaks matching the standard JCPD (Joint Committee on Powder Diffraction Standards) card number 31-1238 [61,62]. The bonding configuration and element analysis were determined by XPS, which allowed confirmation of the surface composition and chemical states of the nanoparticles. Figure S4a shows two band peaks corresponding to $\mathrm{Ag} 3 \mathrm{~d} 3 / 2$ and $\mathrm{Ag} 3 \mathrm{~d} 5 / 2$ at 371.38 and $365.38 \mathrm{eV}$, respectively. Figure S4b shows the XPS Cl spectrum with two peaks at 197.48 and $195.88 \mathrm{eV}$, belonging to $\mathrm{Cl} 2 \mathrm{p} 1 / 2$ and $\mathrm{Cl} 2 \mathrm{p} 3 / 2$, respectively. These binding energy values and the obtained $\mathrm{Ag} / \mathrm{Cl}$ ratio of 0.99 indicate that the nanocatalyst is $\mathrm{AgCl}$ [63]. 

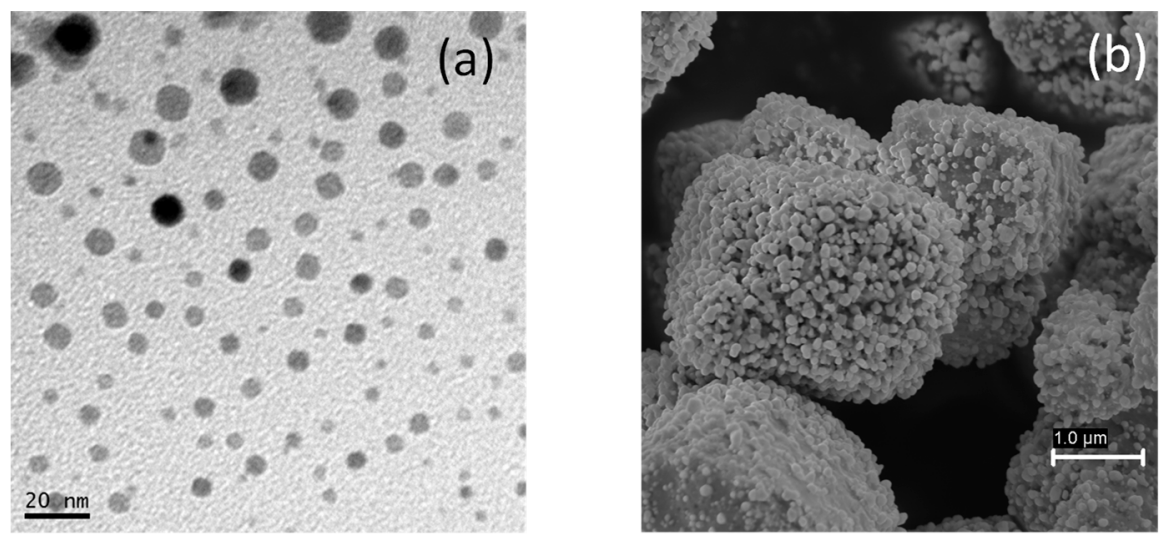

Figure 4. AgCl nanoparticles characterization: (a) TEM image, (b) SEM image.

\subsection{Characterization of $\mathrm{TiO}_{2} @ \mathrm{Fe}_{3} \mathrm{O}_{4}$ and $\mathrm{AgCl} @ \mathrm{Fe}_{3} \mathrm{O}_{4}$ Nanocomposites}

Figure 5a shows a TEM image for $\mathrm{TiO}_{2} @ \mathrm{Fe}_{3} \mathrm{O}_{4}$. The nanocomposite shows a regular, almost spherical morphology with a size distribution between 20 and $50 \mathrm{~nm}$. Figure $5 \mathrm{~b}$ and Figure S5 show SEM and EDS spectra, respectively. In Figure S5, besides the peaks corresponding to $\mathrm{Fe}, \mathrm{O}$ and $\mathrm{Ti}$ from the nanocomposite, $\mathrm{Cu}$ peaks from the copper grid are also observed. The XRD patterns of the prepared $\mathrm{TiO}_{2} @ \mathrm{Fe}_{3} \mathrm{O}_{4}$ nanocomposite are shown in Figure S6. The diffraction peaks that appear for $\mathrm{Fe}_{3} \mathrm{O}_{4}$ correspond to the standard JCPD card number 39-1346. In the case of $\mathrm{TiO}_{2}$. (P25-Degussa, $20 \%$ rutile and $80 \%$ anatase), the peaks match a standard for rutile, JCPD card number 21-1273, and for anatase, JCPD card number 21-1272. Finally, XPS was used to confirm the surface composition (Ti and Fe) and the chemical states of the nanocomposite. As can be seen, the binding energies in Figure $\mathrm{S} 7 \mathrm{a}, \mathrm{b}$ can be assigned to $\mathrm{Fe}_{3} \mathrm{O}_{4}$ and $\mathrm{TiO}_{2}$. The characteristic peaks of $\mathrm{Fe} 2 \mathrm{p} 3 / 2$, Fe 2p1/2, Ti $2 \mathrm{p} 1 / 2$, and Ti2p3/2 are at $724,710,464.59$, and $458.92 \mathrm{eV}$, respectively [38,64].
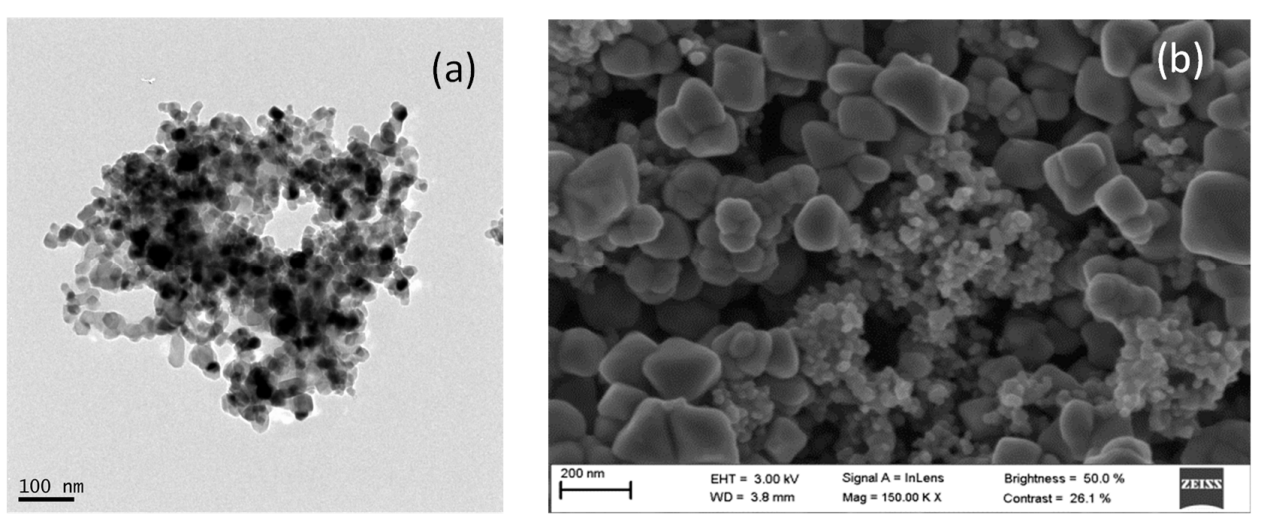

Figure 5. $\mathrm{TiO}_{2} @ \mathrm{Fe}_{3} \mathrm{O}_{4}$ nanocomposite: (a) TEM image, (b) SEM image.

Figure 6a shows a TEM image of the $\mathrm{AgCl} @ \mathrm{Fe}_{3} \mathrm{O}_{4}$ nanocomposite. The formation of mainly spherical aggregates with a size distribution between 10 and $40 \mathrm{~nm}$ is observed. Figure 6b and Figure S8 show an SEM image and EDS spectrum. The peaks shown in Figure $\mathrm{S} 8$ are those corresponding to $\mathrm{Fe}, \mathrm{O}, \mathrm{Cl}$ and $\mathrm{Ag}$ from the nanocomposite, and the $\mathrm{Cu}$ peak comes from the copper grid. The XRD patterns of the prepared $\mathrm{AgCl} @ \mathrm{Fe}_{3} \mathrm{O}_{4}$ nanocomposite are shown in Figure S9. The diffraction peaks for $\mathrm{Fe}_{3} \mathrm{O}_{4}$ correspond to the standard JCPD card number 39-1346, and for $\mathrm{AgCl}$, to the standard JCPD card number 31-1238 (chlorargyrite) [38,61-64]. Furthermore, XPS surface analysis was also used to confirm the surface composition and chemical states of the nanocomposite. Figure S10a shows the spectrum with binding energies at the characteristic peaks of $\mathrm{Ag} 3 \mathrm{~d} 3 / 2$ and $\mathrm{Ag}$ $3 \mathrm{~d} 5 / 2$ at 373.91 and $367.92 \mathrm{eV}$, respectively. Figure S10b shows the peaks of Fe 2p3/2 and Fe 2 p1 $/ 2$ at 724 and $710 \mathrm{eV}$, respectively $[38,63,64]$. 

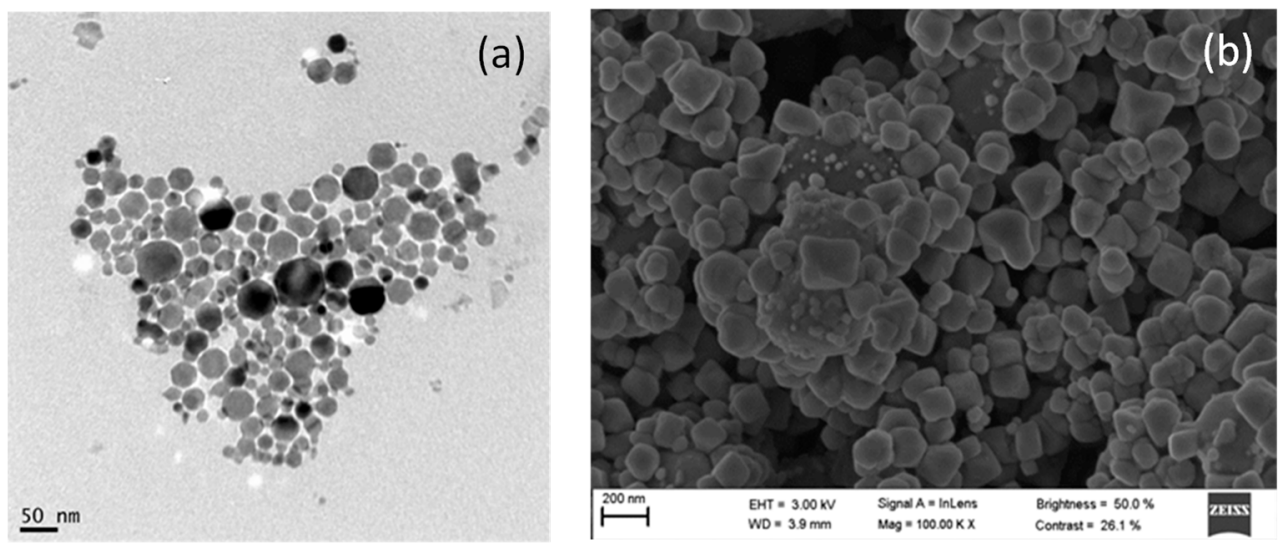

Figure 6. $\mathrm{AgCl} @ \mathrm{Fe}_{3} \mathrm{O}_{4}$ nanocomposite: (a) TEM image, (b) SEM image.

\subsection{Photocatalytic Degradation of ATL with AgCl Nanoparticles}

\subsubsection{Degradation Tests}

The degradation of an aqueous solution with $10 \mathrm{ppm}$ of ATL was carried out firstly using only UV irradiation, secondly with a nanoparticle concentration of $0.75 \mathrm{~g} \cdot \mathrm{L}^{-1}$ in the dark, and finally using the same concentration of $\mathrm{AgCl}$ nanoparticles under UV irradiation. Concentrations were determined by HPLC. Figure 7 shows the variation of ATL concentration with time for all the cases studied. As shown, in the case of the photolysis process (without catalyst), the degradation was very slow, only 5\% and 70\% were achieved in 15 and $90 \mathrm{~min}$, respectively. More than $240 \mathrm{~min}$ were required to achieve a practically complete degradation. In the case of the study in the dark, a negligible decrease in the concentration, mainly due to adsorption of ATL, was observed. The photocatalytic degradation of ATL with $\mathrm{AgCl}$ nanoparticles allowed a total and quick degradation (82\% in $15 \mathrm{~min}, 98 \%$ in $45 \mathrm{~min}$ ). Therefore, the presence of nanoparticles significantly accelerates ATL removal efficiency, decreasing reaction times, energy consumption, and process costs.

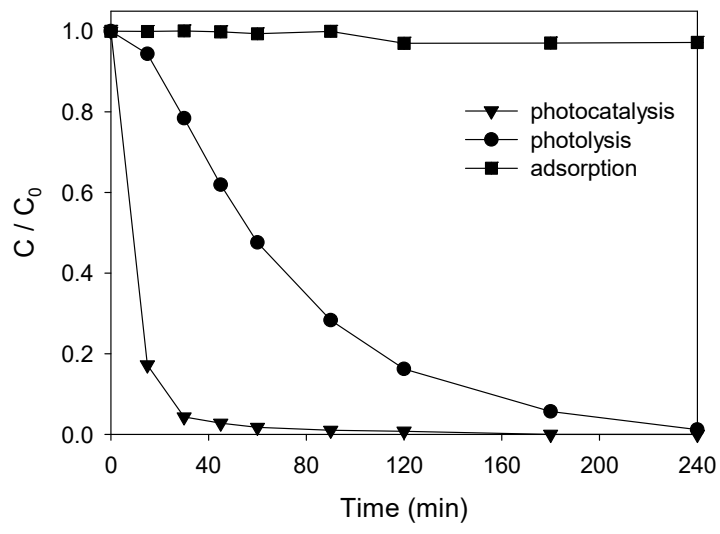

Figure 7. Comparison of ATL degradation methods.

The degradation of the aqueous solution with $10 \mathrm{ppm}$ of ATL and $0.75 \mathrm{~g} \cdot \mathrm{L}^{-1}$ of $\mathrm{AgCl}$ can be easily observed in the progressive evolution of UV-visible absorption spectra (Figure 8). The remarkable decrease in the absorbance peak at $224 \mathrm{~nm}$ over time indicates a very significative degradation of ATL, thus confirming the catalyst's excellent photocatalytic activity under UV light irradiation. 


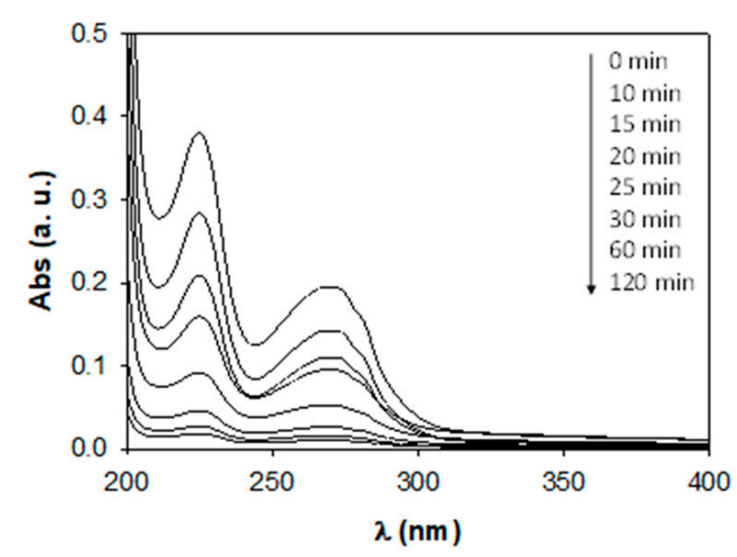

Figure 8. Variation of the UV-Vis absorption spectrum during the degradation of $10 \mathrm{ppm}$ of ATL with $0.75 \mathrm{~g} \cdot \mathrm{L}^{-1}$ of $\mathrm{AgCl}$.

With the aim of comparing the proposed nanocatalyst with other commonly used ones, new tests were carried out using $\mathrm{TiO}_{2}$ (P25-degussa) and $\mathrm{Fe}_{2} \mathrm{O}_{3}$ nanoparticles. The results obtained can be seen in Figure 9. A total degradation of ATL was achieved after $45 \mathrm{~min}$ in the case of $\mathrm{TiO}_{2}$, a slightly higher value than in the case of $\mathrm{AgCl}$ that, at the same time, achieved a degradation of about $98 \%$. However, as previously reported $[65,66]$, suspensions of $\mathrm{TiO}_{2}$ nanoparticles in water form a highly stable hydrocolloid that makes separation of the nanoparticles from water difficult. Therefore, the recovery and reuse of this nanocatalyst become more complicated and the process becomes less efficient. In the case of $\mathrm{Fe}_{2} \mathrm{O}_{3}$, with a clearly lower reduction in the ATL concentration, the process cannot be considered competitive.

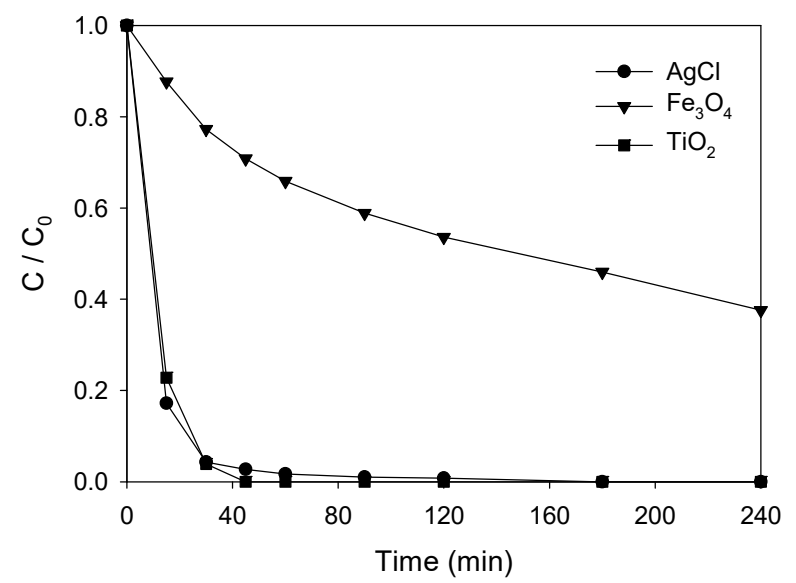

Figure 9. Comparison of nanocatalysts $\left(0.75 \mathrm{~g} \cdot \mathrm{L}^{-1}\right)$ in the photocatalytic degradation of ATL (10 ppm) in aqueous solutions.

\subsubsection{Influence of Operational Parameters}

In order to analyze the effect of different variables on the performance of the degradation of ATL, some tests were conducted as reflected in the following subsections.

\section{AgCl Concentration}

Aqueous solutions of ATL (10 ppm) were submitted to photocatalytic degradation using $\mathrm{AgCl}$ nanoparticle concentrations ranging from 0.25 to $1 \mathrm{~g} \mathrm{~L}^{-1}$. Figure 10 clearly shows that at a given time, an increase in nanoparticle concentration causes an increase in the degradation percentage. Total degradation of ATL was achieved in all the experiments. However, the increase in nanocatalyst concentration from 0.25 to $1 \mathrm{~g} \cdot \mathrm{L}^{-1}$ reduced the 
required time for complete degradation from 180 to $25 \mathrm{~min}$. As shown in Figure 10, the adsorption before light irradiation has a very small influence on the degradation process.

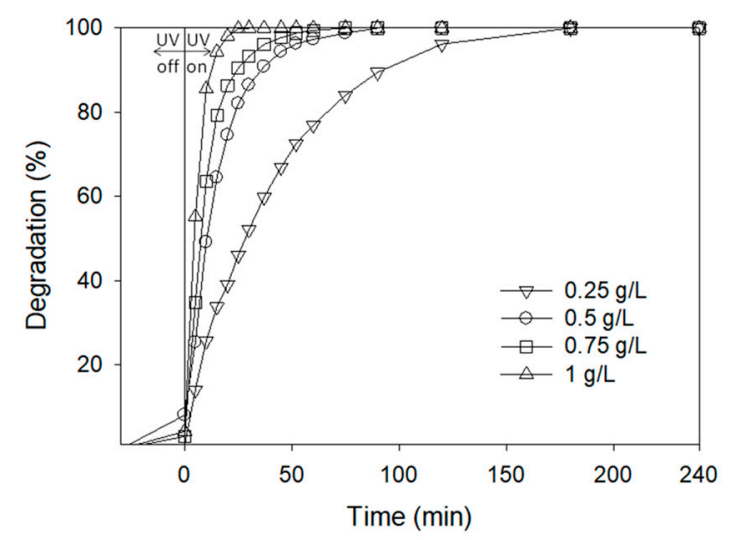

Figure 10. ATL degradation (\%) using different concentrations of nanocatalyst. Initial ATL concentration: $10 \mathrm{ppm}$.

\section{ATL Initial Concentration}

Aqueous solutions of different concentrations of ATL (ranging from 5 to 20 ppm) were submitted to photocatalytic degradation using $0.75 \mathrm{~g} \cdot \mathrm{L}^{-1}$ of $\mathrm{AgCl}$ as a nanocatalyst. Figure 11 shows the percentage of degradation achieved after 30 min under UV light irradiation (a preliminary period of $30 \mathrm{~min}$ in the darkness was always maintained). As shown, degradations of $92 \%, 93 \%, 82 \%$, and $60 \%$ were obtained for solutions with 5,10 , 15 , and $20 \mathrm{ppm}$ of initial ATL concentration, respectively. The effect of this parameter on degradation is not significant up to $10 \mathrm{ppm}$, but higher concentrations for the same nanocatalytic load and the same exposure time to UV light irradiation are associated with a lower degradation percentage.

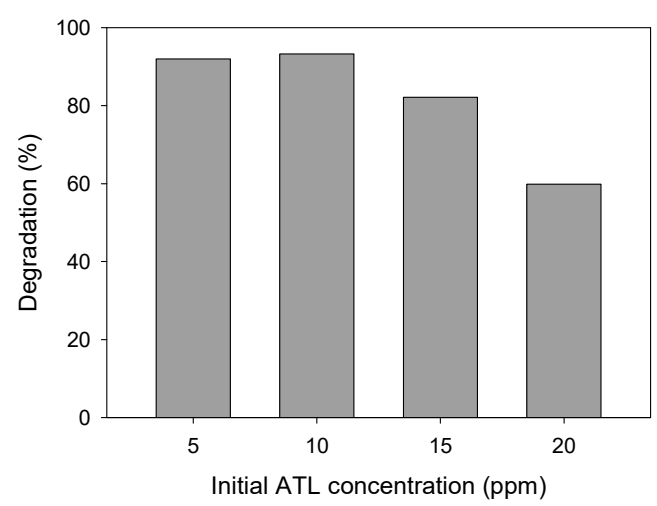

Figure 11. ATL degradation (\%) using different concentrations of contaminant. $\mathrm{AgCl}$ nanoparticles concentration: $10 \mathrm{ppm}$.

pH Solution

To simulate different types of wastewaters, the $\mathrm{pH}$ of the aqueous solutions containing ATL was varied using the required amount of sulfuric acid or sodium hydroxide. The natural $\mathrm{pH}$ of $10 \mathrm{ppm}$ ATL solution was 5.5 and it was varied to obtain values of 3 and 7.5. Figure 12 shows the results of degradation (30 min) using $0.75 \mathrm{~g} \cdot \mathrm{L}^{-1}$ of $\mathrm{AgCl}$ as a nanocatalyst. The degradation achieved in a solution at acidic $\mathrm{pH}$ was slightly lower than in the case of natural $\mathrm{pH}(86 \%$ and $93 \%$, respectively). With the increase in $\mathrm{pH}$ to 7.5 to obtain a slightly basic medium, the degradation decreased to $73 \%$. Similar behavior was previously reported by Bhatia et al. [67]. 


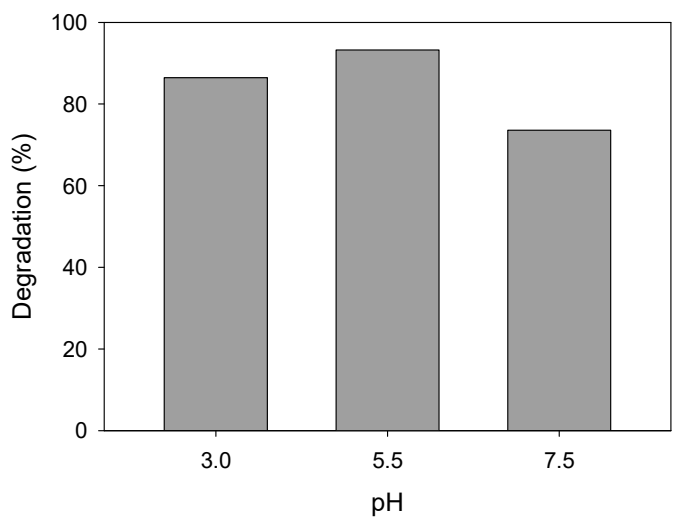

Figure 12. ATL degradation (\%) at different $\mathrm{pH}$ aqueous solutions. Initial ATL concentration: $10 \mathrm{ppm}$; $\mathrm{AgCl}$ nanoparticles concentration: $0.75 \mathrm{~g} \cdot \mathrm{L}^{-1}$.

\section{Addition of Oxidizing Agents}

To evaluate the effect of the addition of oxidizing agents on the photocatalytic process, besides the standard experiment where helium was bubbled to avoid the presence of oxidizing experiments, two new tests were developed where hydrogen peroxide was added or air (oxygen source) was bubbled. In all the cases, the initial concentration of ATL was $10 \mathrm{ppm}$ and nanoparticle concentration was $0.75 \mathrm{~g} \cdot \mathrm{L}^{-1}$. When air was bubbled, the degradation at $30 \mathrm{~min}$ slightly increased from $93 \%$ to $95.5 \%$ (Figure 13). When hydrogen peroxide $\left(\mathrm{H}_{2} \mathrm{O}_{2}\right)$ was added $(5 \mathrm{mM})$, total degradation was achieved in the same period of time. A similar effect was previously found by $\mathrm{Li}$ et al. [68].

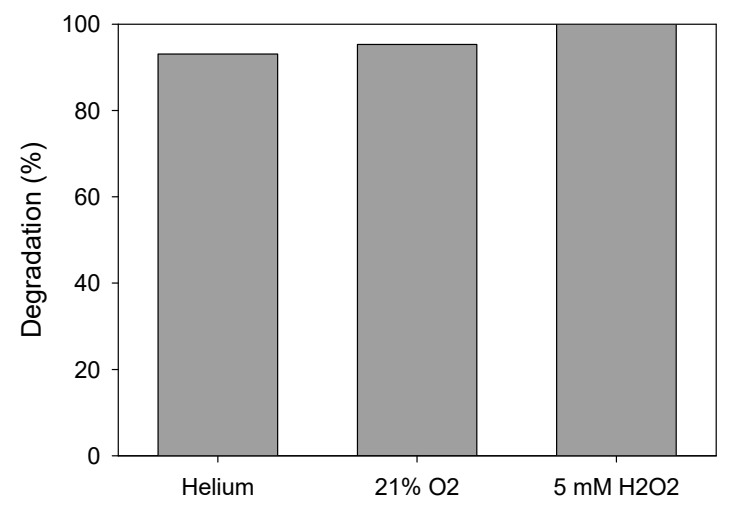

Figure 13. ATL degradation (\%) with and without oxidizing agents. Initial ATL concentration: $10 \mathrm{ppm} ; \mathrm{AgCl}$ concentration: $10 \mathrm{ppm}$.

\subsubsection{Durability of the Nanophotocatalyst}

To achieve an economical process, it is important to evaluate the possibility of reusing the catalyst. Three cycles of degradation were carried out to analyze catalyst durability and efficiency. After each run of degradation (10 ppm ATL, $\left.0.75 \mathrm{~g} \cdot \mathrm{L}^{-1} \mathrm{AgCl}\right)$, the nanoparticles were separated from the aqueous solution by centrifugation, washed with water, and dried at $100{ }^{\circ} \mathrm{C}$ for $12 \mathrm{~h}$. The nanocatalyst was then used in a subsequent degradation process under identical conditions. As can be seen in Figure 14, after the first degradation experiment, in which $93 \%$ degradation was achieved, the efficiency of the process decreased to $75 \%$. No further decrease was detected. Part of the reduction in the efficiency is likely due to the loss of nanoparticles in the separation process. 


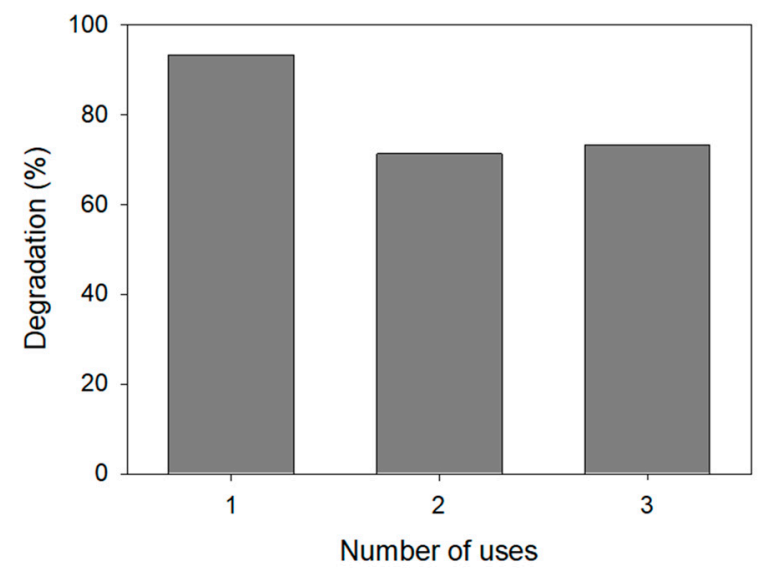

Figure 14. Degradation as a function of the number of uses of the nanocatalyst.

\subsubsection{Kinetics}

The kinetics of the degradation process were studied through the evolution of the ATL concentration with time. The study was carried out (10 ppm ATL, $0.75 \mathrm{~g} \cdot \mathrm{L}^{-1} \mathrm{AgCl}$ ) by taking samples of the liquid phase at different times and analyzing them by HPLC. The results are shown in Figure 15a. Obtained data were adjusted to a pseudo-first-order reaction,

$$
-\ln \left(\frac{C}{C_{0}}\right)=k_{a p p} \cdot t
$$

where $k_{a p p}$ is the pseudo-first-order rate coefficient $\left(\min ^{-1}\right), t$ is the degradation time, and $C$ and $C_{0}$ are the ATL concentrations at time $t$ and at the beginning of the process, respectively. Figure $15 \mathrm{~b}$ shows $-\ln \left(C / C_{0}\right)$ as a function of time. A linear fit, $R^{2}>0.99$, led to a pseudo-first-order kinetic coefficient of $0.0833 \mathrm{~min}^{-1}$. Kinetic tests were also carried out with the same ATL concentration but different concentrations of nanoparticles $(0.25$, 0.5 , and $\left.1 \mathrm{~g} \cdot \mathrm{L}^{-1}\right)$. In all cases, the linear fits were satisfactory and pseudo-first-order kinetic coefficients were calculated. The results are shown in Figure 15c. As expected, the coefficient increases with the increase in the nanocatalyst load.
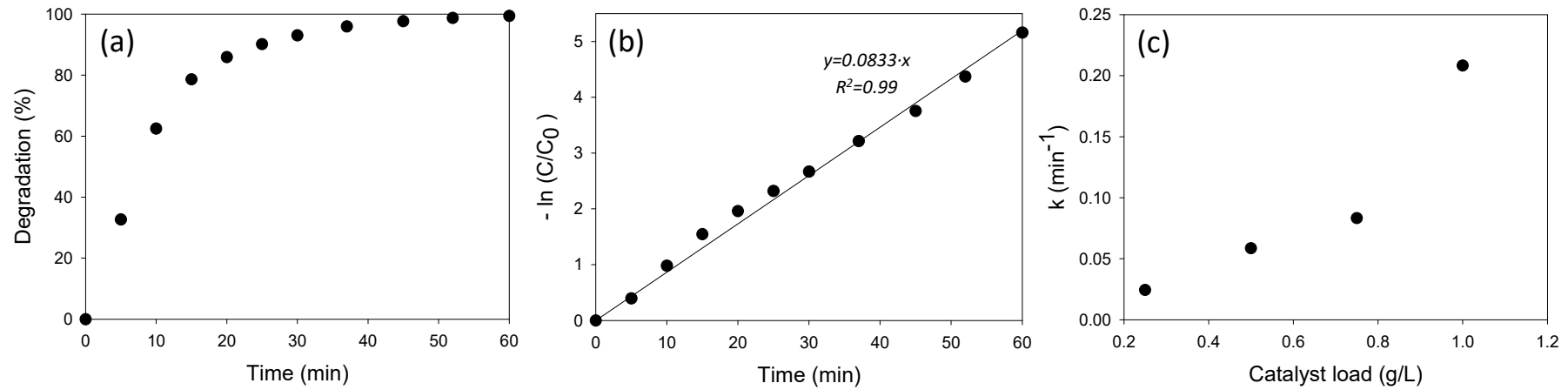

Figure 15. Kinetic studies of photocatalytic degradation of ATL: (a) Degradation with time (10 ppm ATL and $0.75 \mathrm{~g} \cdot \mathrm{L}^{-1}$ of $\mathrm{AgCl}$ ). (b) Fit to a pseudo-first-order reaction. (c) Pseudo-first-order coefficients as a function of nanocatalyst load.

\subsubsection{Degradation Products}

Degradation products were identified as a means to evaluate possible pathways of $\mathrm{AgCl}$-mediated ATL transformation. The HPLC chromatogram of the irradiated sample revealed some new peaks compared to the non-irradiated sample, which was indicative of the formation of intermediates. In order to determine as many intermediates as possible, aliquots at different irradiation times from the degradation process were analyzed by LC-Q-TOF-MS and MS/MS as described before [69,70]. Briefly, a list of possible entities for 
each chromatogram was generated using the algorithm "Find by molecular feature". Then, a comparison between the control group (aliquots at time 0 ) and aliquots at different times was performed using the MassProfiler Professional software. Next, empirical formulae were generated for the potential degradation products with cut-off values of mass error $<5 \mathrm{ppm}$ and score $>80$ (100 being a perfect match of accurate mass and isotopic distribution). A list of the detected transformation products and identification parameters is shown in Table 1. As shown, the empirical formula can be applied with a high degree of certainty, with score values higher than $85 \%$ and mass errors lower than $3.5 \mathrm{ppm}$.

Table 1. List of ATL degradation compounds and their identification parameters.

\begin{tabular}{ccccc}
\hline Product & $\begin{array}{c}\text { Experimental } \\
\mathbf{m} / \mathbf{z}\end{array}$ & $\begin{array}{c}\text { Proposed } \\
\text { Formula }\end{array}$ & $\begin{array}{c}\text { Mass Error } \\
(\mathbf{p p m})\end{array}$ & Score \\
\hline Atenolol & 267.1705 & $\mathrm{C}_{14} \mathrm{H}_{22} \mathrm{O}_{3} \mathrm{~N}_{2}$ & -0.33 & 99.92 \\
A-1 & 283.1648 & $\mathrm{C}_{14} \mathrm{H}_{22} \mathrm{O}_{4} \mathrm{~N}_{2}$ & 3.48 & 92.39 \\
A-2 & 299.1595 & $\mathrm{C}_{14} \mathrm{H}_{22} \mathrm{O}_{5} \mathrm{~N}_{2}$ & 2.05 & 85.5 \\
A-3 & 281.1499 & $\mathrm{C}_{14} \mathrm{H}_{20} \mathrm{O}_{4} \mathrm{~N}_{2}$ & -1 & 86.34 \\
A-4 & 152.0703 & $\mathrm{C}_{8} \mathrm{H}_{9} \mathrm{O}_{2} \mathrm{~N}$ & 0.97 & 85.13 \\
A-5 & 134.1178 & $\mathrm{C}_{6} \mathrm{H}_{15} \mathrm{O}_{2} \mathrm{~N}$ & -1.46 & 87.74 \\
A-6 & 238.1439 & $\mathrm{C}_{13} \mathrm{H}_{19} \mathrm{O}_{3} \mathrm{~N}$ & 0.96 & 95.32 \\
A-7 & 254.1387 & $\mathrm{C}_{13} \mathrm{H}_{19} \mathrm{O}_{4} \mathrm{~N}$ & 3.02 & 89.79 \\
\hline
\end{tabular}

The proposed structures are based on the interpretation of the MS/MS spectra and the literature (Figure 16). All the identified products have been previously reported in the literature [31,71-73]. Products A-1 and A-2 consist of the addition of one or two hydroxyl groups to the aromatic ring. After $40 \mathrm{~min}$, these products were degraded, and at longer exposure times, product A-3 was produced by oxidation of the hydroxyl group of the aliphatic chain to the ketone. Two isomers were observed for these products. Products A-4 and A-5 were formed through hydroxylation followed by the cleavage of the bond between the oxygen and the aromatic carbon. The product A- 5 was stable at long degradation times, while product A-4 disappeared. The benzaldehyde derivative product A- 6 was produced after the loss of the amide group, hydroxylation, and oxidation. Further hydroxylation of this product resulted in the formation of product A-7. Three isomers of A-7 were observed. Thus, at long reaction times (after $180 \mathrm{~min}$ ), the most persistent degradation products were A- 5 and A-3.

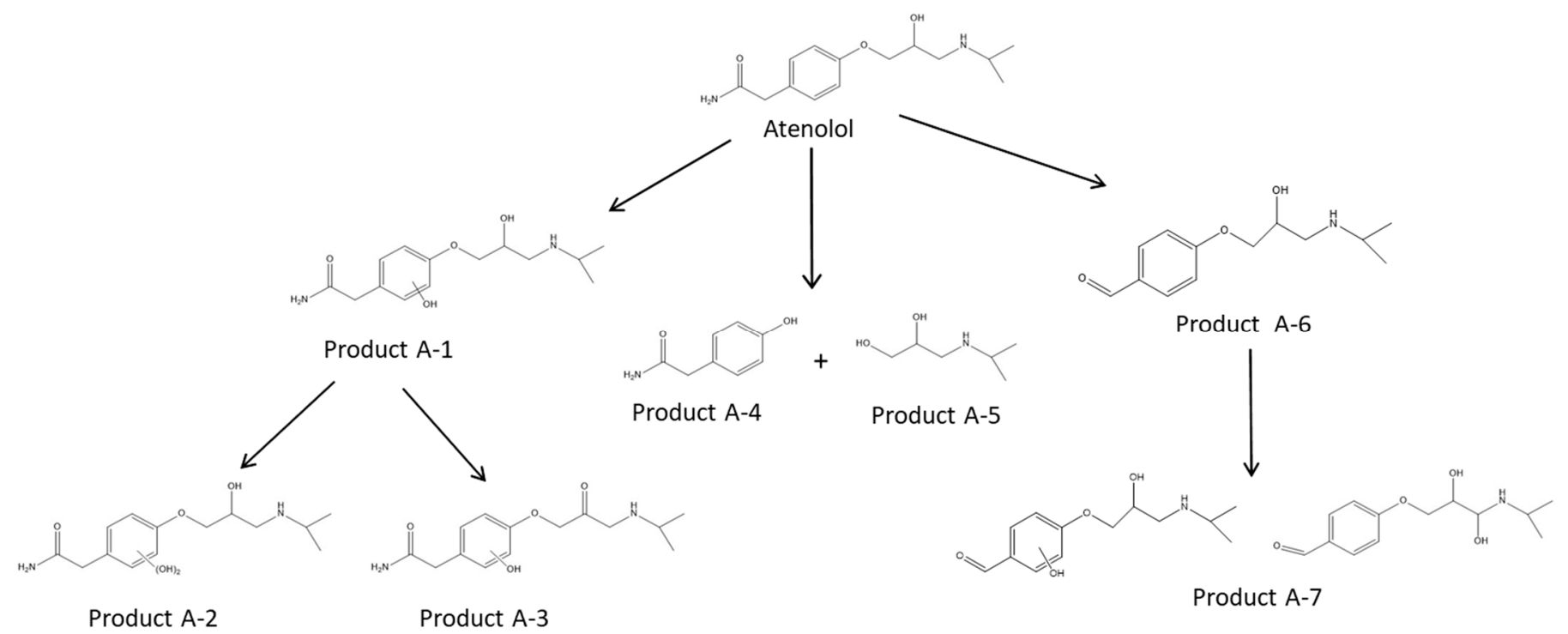

Figure 16. Proposed mechanism for the degradation of ATL. 


\subsection{Photocatalytic Degradation of ATL with $\mathrm{AgCl} @ \mathrm{Fe}_{3} \mathrm{O}_{4}$ or $\mathrm{TiO}_{2} @ \mathrm{Fe}_{3} \mathrm{O}_{4}$ Nanocomposites}

$\mathrm{AgCl}$ nanoparticles were separated and re-used in this work, but the process took several stages to complete. Thus, a preliminary study was carried out to analyze the efficiency of magnetic nanocomposites, since the industrial recovery of the catalyst would be facilitated. Thus, $\mathrm{Fe}_{3} \mathrm{O}_{4}$ was combined with $\mathrm{AgCl}$ and also $\mathrm{TiO}_{2}$ due to its great degradation capacity associated with a difficult separation $[65,66]$. For comparative purposes, the same degradation conditions (10 ppm ATL, $0.75 \mathrm{~g} \cdot \mathrm{L}^{-1}$ nanocatalyst) were selected. Figure 17 shows the results obtained with these nanocomposites and the corresponding nanoparticles. Some degradation results are numerically presented in Table 2. As shown in Section 3.3.1, $\mathrm{AgCl}$ and $\mathrm{TiO}_{2}$ nanoparticles offer similar degradation results, with a slightly higher velocity in the case of the latter, and degradation obtained with $\mathrm{Fe}_{2} \mathrm{O}_{3}$ is very limited. Regarding nanocomposites, it can be observed that they present an intermediate behavior between their two constituents. Thus, comparing nanocomposites and nanoparticles, the latter show higher degradation capacity. This was expected because at the same concentration of the nanocatalyst, nanocomposites have $\mathrm{Fe}_{3} \mathrm{O}_{4}$ with low photocatalytic activity. However, these nanocomposites have a great advantage in the separation process and subsequent reuse. Their magnetic properties allow for an easy separation with the help of a simple magnetic field, thus avoiding the expensive process of ultracentrifugation. This is shown in Figure 18. A practically complete separation from water was achieved in a matter of seconds using a simple magnet.

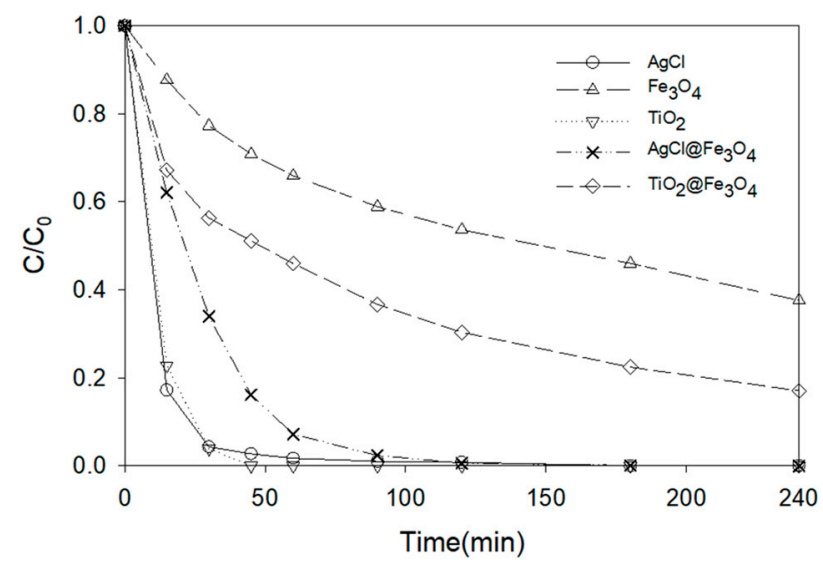

Figure 17. Degradation performances $\left(C / C_{0}\right)$ as a function of time using different nanocatalysts (the lines are only to facilitate the visualization of the results).

Comparing $\mathrm{AgCl} @ \mathrm{Fe}_{2} \mathrm{O}_{3}$ and $\mathrm{TiO}_{2} @ \mathrm{Fe}_{3} \mathrm{O}_{4}$ nanocomposites, the first clearly led to better results. After $30 \mathrm{~min}$ of reaction, the degradation achieved with $\mathrm{AgCl}_{\mathrm{C}} \mathrm{Fe}_{3} \mathrm{O}_{4} \mathrm{MNCs}$ is $66 \%$ and with $\mathrm{TiO}_{2} @ \mathrm{Fe}_{3} \mathrm{O}_{4}$ is $44 \%$ (see Table 2). Moreover, total degradation was not possible in this last case, whereas the nanocomposite with silver achieved it in about $95 \mathrm{~min}$.

Table 2. Degradation achieved by different nanocatalysts after $30 \mathrm{~min}$ under UV-Vis light (Initial concentration of ATL, 10 ppm; nanomaterials, $0.75 \mathrm{~g} / \mathrm{L}$ ).

\begin{tabular}{ccc}
\hline Catalyst & Size (nm) & Degradation-30 min (\%) \\
\hline $\mathrm{AgCl}$ & $<20$ & 95.7 \\
$\mathrm{TiO}_{2}$ & $<21$ & 96.1 \\
$\mathrm{Fe}_{3} \mathrm{O}_{4}$ & $<100$ & 23.4 \\
$\mathrm{Fe}_{3} \mathrm{O}_{4} @ \mathrm{AgCl}$ & $<100$ & 66.0 \\
$\mathrm{Fe}_{3} \mathrm{O}_{4 @} \mathrm{TiO}_{2}$ & $<100$ & 43.7 \\
\hline
\end{tabular}




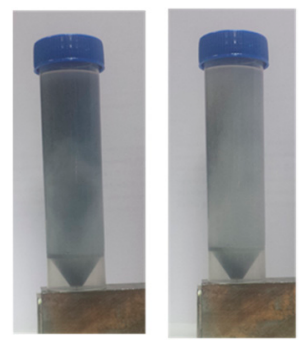

Figure 18. Magnetic separation of nanocomposites.

\section{Conclusions}

The use of the IL $\left[\mathrm{P}_{6,6,6,14}\right] \mathrm{Cl}$ allowed the preparation of simple nanoparticles such as $\mathrm{AgCl}$ and also more complex nanocomposites $\left(\mathrm{AgCl} @ \mathrm{Fe}_{2} \mathrm{O}_{3}\right.$ and $\left.\mathrm{TiO}_{2} @ \mathrm{Fe}_{3} \mathrm{O}_{4}\right)$ at room pressure and low temperatures without the need for any other solvent. Among many other applications, the use of these nanomaterials as photocatalysts in the degradation of emerging pollutants is promising.

Selecting ATL as a model of a pharmaceutical pollutant in wastewater, it was found that UV-C irradiation and a catalyst are required to achieve competitive results. The use of $0.75 \mathrm{~g} \cdot \mathrm{L}^{-1}$ of $\mathrm{AgCl}$ nanoparticles led to a degradation of ATL of $96 \%$ in aqueous solution (10 ppm) after $30 \mathrm{~min}$ and a practically total degradation in about $45 \mathrm{~min}$. Slightly better results were obtained with $\mathrm{TiO}_{2}$ nanoparticles but separation was more difficult.

Selecting $\mathrm{AgCl}$ as a nanocatalyst, it was found that the increase in its concentration accelerates the degradation process. Higher concentrations of ATL in the wastewater mean lower degradation if the nanocatalyst concentration is fixed. A natural $\mathrm{pH}$ of the solution (5.5) led to the greatest degradation rates. The use of oxidizing agents slightly increases the degradation rate, at the expense of increasing the risk and cost of the process. The catalyst can be separated by centrifugation and re-used at least three times with a small loss of efficiency. The degradation process follows first-order kinetics. The main reactions occurring during degradation were ipso-hydroxylation and subsequent fragmentation, hydroxylation with detachment of the amide moiety and further oxidation, and introduction of hydroxyl groups into the aromatic ring or the alkyl chain.

Magnetic composites $\left(\mathrm{AgCl} @ \mathrm{Fe}_{2} \mathrm{O}_{3}\right.$ and $\mathrm{TiO}_{2} @ \mathrm{Fe}_{3} \mathrm{O}_{4}$ ) led to worse degradation results than $\mathrm{AgCl}$ or $\mathrm{TiO}_{2}$ due to the limited photocatalytic activity of $\mathrm{Fe}_{3} \mathrm{O}_{4}$. Of the two, the silver nanocomposites clearly performed better and total degradation was achieved after about $95 \mathrm{~min}$, but this was far slower than in the case of $\mathrm{AgCl}$ alone. However, the nanocomposites have a great advantage in the separation process, since their magnetism makes separation simple and quick.

Supplementary Materials: The following are available online at https:/ /www.mdpi.com/2079-499 1/11/2/411/s1, Figure S1: $1 \mathrm{H}$ and $13 \mathrm{C}$ spectra of $\left[\mathrm{P}_{6,6,6,14}\right] \mathrm{Cl}$, Figure S2: UV-Vis-absorbance of $\mathrm{AgCl}$ nanoparticles, Figure S3: XRD diffraction pattern of AgCl nanoparticles, Figure S4: XPS spectra of $\mathrm{AgCl}$ nanoparticles: $\mathrm{Ag} 3 \mathrm{~d}(\mathrm{a})$ and $\mathrm{Cl} 2 \mathrm{p}$ (b), Figure S5: EDS spectrum of $\mathrm{TiO}_{2} @ \mathrm{Fe}_{3} \mathrm{O}_{4}$ nanocomposite, Figure S6: XRD patterns of $\mathrm{TiO}_{2} @ \mathrm{Fe}_{3} \mathrm{O}_{4}$ nanocomposite, Figure S7: XPS spectra of $\mathrm{TiO}_{2} @ \mathrm{Fe}_{3} \mathrm{O}_{4}$ nanocomposite: Fe2p (a) and Ti2p (b), Figure S8: EDS spectrum of $\mathrm{AgCl} @ \mathrm{Fe}_{3} \mathrm{O}_{4}$ nanocomposite, Figure S9: XRD patterns of $\mathrm{AgCl} @ \mathrm{Fe}_{3} \mathrm{O}_{4}$ nanocomposite, Figure S10: XPS spectra of $\mathrm{AgCl} @ \mathrm{Fe}_{3} \mathrm{O}_{4}$ nanocomposite: Ag3d (a) and Fe2p (b)

Author Contributions: Experimental, R.C.; analatical studies: R.R.; writing, R.R., E.R. and A.S.; project coordinator, E.R.; funding acquisition, A.S. All authors have read and agreed to the published version of the manuscript.

Funding: This research was funded by Xunta de Galicia through grant numbers ED431B 2020/21, ED431B 2020/21 and ED431C2017/36, the Spanish Agencia Estatal de Investigación (ref. CTM201784763-C3-R-2), and FEDER/ERDF funds (European Regional Development Fund).

Conflicts of Interest: The authors declare no conflict of interest. 


\section{References}

1. Daughton, C.G.; Ternes, T.A. Pharmaceuticals and personal care products in the environment: Agents of subtle change? Environ. Health Perspect. 1999, 107, 907-938. [CrossRef] [PubMed]

2. Ellis, J. Pharmaceutical and personal care products (PPCPs) in urban receiving waters. Environ. Pollut. 2006, 144, 184-189. [CrossRef]

3. Ebele, A.J.; Abdallah, M.A.-E.; Harrad, S. Pharmaceuticals and personal care products (PPCPs) in the freshwater aquatic environment. Emerg. Contam. 2017, 3, 1-16. [CrossRef]

4. Pal, A.; He, Y.; Jekel, M.; Reinhard, M.; Gin, K.Y.-H. Emerging contaminants of public health significance as water quality indicator compounds in the urban water cycle. Environ. Int. 2014, 71, 46-62. [CrossRef]

5. Recsetara, M.S.; Fitzsimmonsb, K.M.; Cuello, J.L.; Hoppe-Jones, C.; Snyderc, S.A. Evaluation of a recirculating hydroponic bed bioreactor for removal of contaminants of emerging concern from tertiary-treated wastewater effluent. Chemosphere 2021, 128121. [CrossRef]

6. Petrie, B.; Barden, R.; Kasprzyk-Hordern, B. A review on emerging contaminants in wastewaters and the environment: Current knowledge, understudied areas and recommendations for future monitoring. Water Res. 2015, 72, 3-27. [CrossRef]

7. Geissen, V.; Mol, H.G.J.; Klumpp, E.; Umlauf, G.; Nadal, M.; Van Der Ploeg, M.; Van De Zee, S.E.; Ritsema, C.J. Emerging pollutants in the environment: A challenge for water resource management. Int. Soil Water Conserv. Res. 2015, 3, 57-65. [CrossRef]

8. Roberts, J.; Kumar, A.; Du, J.; Hepplewhite, C.; Ellis, D.J.; Christy, A.G.; Beavis, S.G. Pharmaceuticals and personal care products (PPCPs) in Australia's largest inland sewage treatment plant, and its contribution to a major Australian river during high and low flow. Sci. Total Environ. 2016, 541, 1625-1637. [CrossRef]

9. Gavrilescu, M.; Demnerová, K.; Aamand, J.; Agathos, S.N.; Fava, F. Emerging pollutants in the environment: Present and future challenges in biomonitoring, ecological risks and bioremediation. New Biotechnol. 2015, 32, 147-156. [CrossRef] [PubMed]

10. Yoon, Y.; Westerhoff, P.; Snyder, S.A.; Wert, E.C.; Yoon, J. Removal of endocrine disrupting compounds and pharmaceu-ticals by nanofiltration and ultrafiltration membranes. Desalination 2007, 202, 16-23. [CrossRef]

11. Abdel-Fatah, M.A. Nanofiltration systems and applications in wastewater treatment: Review article. Ain Shams Eng. J. 2018, 9, 3077-3092. [CrossRef]

12. Grassi, M.; Rizzo, L.; Farina, A. Endocrine disruptors compounds, pharmaceuticals and personal care products in urban wastewater: Implications for agricultural reuse and their removal by adsorption process. Environ. Sci. Pollut. Res. 2013, 20, 3616-3628. [CrossRef]

13. Joseph, L.; Jun, B.-M.; Jang, M.; Park, C.M.; Muñoz-Senmache, J.C.; Hernández-Maldonado, A.J.; Heyden, A.; Yu, M.; Yoon, Y. Removal of contaminants of emerging concern by metal-organic framework nanoadsorbents: A review. Chem. Eng. J. 2019, 369, 928-946. [CrossRef]

14. Suarez, S.; Lema, J.M.; Omil, F. Pre-treatment of hospital wastewater by coagulation-flocculation and flotation. Bioresour. Technol. 2009, 100, 2138-2146. [CrossRef] [PubMed]

15. Suarez, S.; Lema, J.M.; Omil, F. Removal of pharmaceutical and personal care products (PPCPs) under nitrifying and de-nitrifying conditions. Water Res. 2010, 44, 3214-3224. [CrossRef]

16. Gardner, M.; Jones, V.; Comber, S.; Scrimshaw, M.D.; Coello-Garcia, T.; Cartmell, E.; Lester, J.; Ellor, B. Performance of UK wastewater treatment works with respect to trace contaminants. Sci. Total Environ. 2013, 456, 359-369. [CrossRef]

17. Mirzaei, A.; Chen, Z.; Haghighat, F.; Yerushalmi, L. Removal of pharmaceuticals from water by homo/heterogonous Fenton-type processes-A review. Chemosphere 2017, 174, 665-688. [CrossRef]

18. Utset, B.; Garcia, J.; Casado, J.; Domènech, X.; Peral, J. Replacement of $\mathrm{H}_{2} \mathrm{O}_{2}$ by $\mathrm{O}_{2}$ in Fenton and photo-Fenton reactions. Chemosphere 2000, 41, 1187-1192. [CrossRef]

19. Esplugas, S.; Bila, D.M.; Krause, L.G.T.; Dezotti, M. Ozonation and advanced oxidation technologies to remove endocrine disrupting chemicals (EDCs) and pharmaceuticals and personal care products (PPCPs) in water effluents. J. Hazard. Mater. 2007, 149, 631-642. [CrossRef]

20. Paucar, N.E.; Kim, I.; Tanaka, H.; Sato, C. Ozone treatment process for the removal of pharmaceuticals and personal care products in wastewater. Ozone Sci. Eng. 2019, 41, 3-16. [CrossRef]

21. Chu, K.H.; Al-Hamadani, Y.; Park, C.M.; Lee, G.; Jang, M.; Jang, A.; Her, N.; Son, A.; Yoon, Y. Ultrasonic treatment of endocrine disrupting compounds, pharmaceuticals, and personal care products in water: A review. Chem. Eng. J. 2017, 327, 629-647. [CrossRef]

22. Pérez, G.; Fernández-Alba, A.; Urtiaga, A.; Ortiz, I. Electro-oxidation of reverse osmosis concentrates generated in tertiary water treatment. Water Res. 2010, 44, 2763-2772. [CrossRef]

23. Urtiaga, A.; Pérez, G.; Ibáñez, R.; Ortiz, I. Removal of pharmaceuticals from a WWTP secondary effluent by ultrafiltration/reverse osmosis followed by electrochemical oxidation of the RO concentrate. Desalination 2013, 331, 26-34. [CrossRef]

24. Duan, X.D.; He, X.X.; Wang, D.; Mezyk, S.P.; Otto, S.C.; Marfil-Vega, R.; Mills, M.A.; Dionysiou, D.D. Decomposition of Iodinated Pharmaceuticals by UV-254 nm-assisted Advanced Oxidation Processes. J. Hazard. Mater. 2017, 323, 489-499. [CrossRef] [PubMed]

25. Baena-Nogueras, R.M.; González-Mazo, E.; Lara-Martín, P.A. Degradation kinetics of pharmaceuticals and personal care products in surface waters: Photolysis vs biodegradation. Sci. Total. Environ. 2017, 643-654. [CrossRef] [PubMed] 
26. Bethi, B.; Sonawane, S.H.; Bhanvase, B.A.; Gumfekar, S.P. Nanomaterials-based advanced oxidation processes for wastewater treatment: A review. Chem. Eng. Process. Process. Intensif. 2016, 109, 178-189. [CrossRef]

27. Bakbolat, B.; Daulbayev, C.; Sultanov, F.; Beissenov, R.; Umirzakov, A.; Mereke, A.; Bekbaev, A.; Chuprakov, I. Recent Developments of $\mathrm{TiO}_{2}$-Based Photocatalysis in the Hydrogen Evolution and Photodegradation: A Review. Nanomaterials 2020, 10, 1790. [CrossRef]

28. Hapeshi, E.; Achilleos, A.; Vasquez, M.; Michael, C.; Xekoukoulotakis, N.; Mantzavinos, D.; Kassinos, D. Drugs degrading photocatalytically: Kinetics and mechanisms of ofloxacin and atenolol removal on titania suspensions. Water Res. 2010, 44, 1737-1746. [CrossRef]

29. Martínez, C.; Canle, M.; Fernández, M.; Santaballa, J.; Faria, J. Kinetics and mechanism of aqueous degradation of carbamazepine by heterogeneous photocatalysis using nanocrystalline $\mathrm{TiO}_{2}, \mathrm{ZnO}$ and multi-walled carbon nanotubes-anatase composites. Appl. Catal. B Environ. 2011, 102, 563-571. [CrossRef]

30. Karunakaran, C.; Dhanalakshmi, R.; Manikandan, G.; Gomathisankar, P. Photodegradation of carboxylic acids on $\mathrm{Al}_{2} \mathrm{O}_{3}$ and $\mathrm{SiO}_{2}$ nanoparticles. Indian J. Chem. Part A Inorg. Phys. Theor. Anal. 2011, 50, 163-170.

31. Jia, Y.; Zhou, L.; Ferronato, C.; Yang, X.; Salvador, A.; Zeng, C.; Chovelon, J.-M. Photocatalytic degradation of atenolol in aqueous titanium dioxide suspensions: Kinetics, intermediates and degradation pathways. J. Photochem. Photobiol. A Chem. 2013, 254, 35-44. [CrossRef]

32. Bodzek, M.; Rajca, M. Photocatalysis in the treatment and disinfection of water. Part I. Theoretical backgrounds/Foto-kataliza w oczyszczaniu i dezynfekcji wody część i. podstawy teoretyczne. Ecol. Chem. Eng. S 2012, 489. [CrossRef]

33. Kolahalam, L.A.; Viswanath, I.K.; Diwakar, B.S.; Govindh, B.; Reddy, V.; Murthy, Y. Review on nanomaterials: Synthesis and applications. Mater. Today Proc. 2019, 18, 2182-2190. [CrossRef]

34. Nasrollahzadeh, M.; Sajjadi, M.; Iravani, S.; Varma, R.S. Green-synthesized nanocatalysts and nanomaterials for water treatment: Current challenges and future perspectives. J. Hazard. Mater. 2021, 401, 123401. [CrossRef] [PubMed]

35. Lu, A.-H.; Salabas, E.-L.; Schüth, F. Magnetic Nanoparticles: Synthesis, Protection, Functionalization, and Application. Angew. Chem. Int. Ed. 2007, 46, 1222-1244. [CrossRef]

36. Behrens, S.; Appel, I. Magnetic nanocomposites. Curr. Opin. Biotechnol. 2016, 39, 89-96. [CrossRef]

37. Wu, W.; Xiao, X.; Zhang, S.; Ren, F.; Jiang, C.Z. Facile method to synthesize magnetic iron oxides $/ \mathrm{TiO}_{2}$ hybrid nanoparticles and their photodegradation application of methylene blue. Nanoscale Res. Lett. 2011, 6, 533. [CrossRef] [PubMed]

38. Álvarez, P.M.; Jaramillo, J.; López-Piñero, F.; Plucinski, P.K. Preparation and characterization of magnetic $\mathrm{TiO}_{2}$ nano-particles and their utilization for the degradation of emerging pollutants in water. Appl. Catal. B Environ. 2010, 100, 338-345. [CrossRef]

39. Shekofteh-Gohari, M.; Habibi-Yangjeh, A. Ultrasonic-assisted preparation of novel ternary $\mathrm{ZnO} / \mathrm{AgI} / \mathrm{Fe}_{3} \mathrm{O}_{4}$ nanocomposites as magnetically separable visible-light-driven photocatalysts with excellent activity. J. Colloid Interface Sci. 2016, 461, 144-153. [CrossRef]

40. Wang, J.; Yang, J.; Li, X.; Wang, D.; Wei, B.; Song, H.; Li, X.; Fu, S. Preparation and photocatalytic properties of magnetically reusable $\mathrm{Fe}_{3} \mathrm{O}_{4} @ \mathrm{ZnO}$ core/shell nanoparticles. Phys. E Low Dimens. Syst. Nanostruct. 2016, 75, 66-71. [CrossRef]

41. Wang, Y.; Hou, Q.; Ju, M.; Li, W. New Developments in Material Preparation Using a Combination of Ionic Liquids and Microwave Irradiation. Nanomaterials 2019, 9, 647. [CrossRef] [PubMed]

42. Khare, V.; Ruby, C.; Sonkaria, S.; Taubert, A. A green and sustainable nanotechnology: Role of ionic liquids. Int. J. Precis. Eng. Manuf. 2012, 13, 1207-1213. [CrossRef]

43. He, Z.; Alexandridis, P. Nanoparticles in ionic liquids: Interactions and organization. Phys. Chem. Chem. Phys. 2015, 17, 18238-18261. [CrossRef]

44. Antonietti, M.; Kuang, D.; Smarsly, B.; Zhou, Y. Ionic Liquids for the Convenient Synthesis of Functional Nanoparticles and Other Inorganic Nanostructures. Angew. Chem. Int. Ed. 2004, 43, 4988-4992. [CrossRef]

45. Scholten, J.D.; Prechtl, M.H.G.; Dupont, J. Formation of Nanoparticles Assisted by Ionic Liquids. In Handbook of Green Chemistry; Wiley: Hoboken, NJ, USA, 2010; Volume 8, pp. 1-31.

46. Duan, X.; Ma, J.-M.; Lian, J.; Zheng, W. The art of using ionic liquids in the synthesis of inorganic nanomaterials. CrystEngComm 2014, 16, 2550-2559. [CrossRef]

47. Rodríguez-Cabo, B.; Rodríguez-Palmeiro, I.; Rodil, R.; Rodil, E.; Arce, A.; Soto, A. Synthesis of AgCl nanoparticles in ionic liquid and their application in photodegradation of Orange II. J. Mater. Sci. 2015, 50, 3576-3585. [CrossRef]

48. Kumar, B.; Smita, K.; Cumbal, L.; Debut, A.; Pathak, R.N. Ionic Liquid Based Silica Tuned Silver Nanoparticles: Novel Approach for Fabrication. Synth. React. Inorg. Met. Chem. 2016, 46, 1265-1271. [CrossRef]

49. Zhou, Y.; Antonietti, M. Synthesis of very small $\mathrm{TiO}_{2}$ nanocrystals in a room-temperature ionic liquid and their self-assembly toward mesoporous spherical aggregates. J. Am. Chem. Soc. 2003, 125, 14960-14961. [CrossRef] [PubMed]

50. Chen, T.; Xie, Z.; Jiang, W.; Jiang, W.; Zhang, W.; Liu, J. Synthesis of $\mathrm{CeO}_{2}$ nanosheets with a room temperature ionic liquid assisted method. J. Adv. Ceram. 2016, 5, 111-116. [CrossRef]

51. Chen, J.; Xia, J.; Di, J.; Ji, M.; Li, H.; Xu, H.; Zhang, Q.; Lu, J. Reactable ionic liquid assisted synthesis of $\mathrm{BiPO}_{4}$ and the influences of solvent on structure, morphology and photocatalytic performance. Colloids Surf. A Phys. Chem. Eng. Asp. 2016, 488, 110-117. [CrossRef] 
52. Xia, J.; Zhao, J.; Chen, J.; Di, J.; Ji, M.; Xu, L.; Chen, Z.; Li, H. Facile fabrication of g-C3N4/BiPO 4 hybrid materials via a reactable ionic liquid for the photocatalytic degradation of antibiotic ciprofloxacin. J. Photochem. Photobiol. A Chem. 2017, 339, 59-66. [CrossRef]

53. Hu, Q.; Ji, M.; Di, J.; Wang, B.; Xia, J.; Zhao, Y.; Li, H. Ionic liquid-induced double regulation of carbon quantum dots modified bismuth oxychloride/bismuth oxybromide nanosheets with enhanced visible-light photocatalytic activity. J. Colloid Interface Sci. 2018, 519, 263-272. [CrossRef]

54. Yin, S.; Ding, Y.; Hu, Q.; Wu, T.; Li, M.; Chen, Y.; Shao, Y.; Di, J.; Wang, B.; Xia, J.; et al. CQDs modified $\mathrm{PbBiO}_{2} \mathrm{Cl}_{\text {nanosheets with }}$ improved molecular oxygen activation ability for photodegradation of organic contaminants. J. Photochem. Photobiol. A Chem. 2019, 382, 111921.

55. Nan, Q.; Huang, S.; Zhou, Y.; Zhao, S.; He, M.; Wang, Y.; Li, S.; Huang, T.; Pan, W. Ionic liquid-assisted synthesis of porous BiOBr microspheres with enhanced visible light photocatalytic performance. Appl. Organomet. Chem. 2018, 32, e4596. [CrossRef]

56. Arce, A.; Soto, A.; Rodil, E.; Rodríguez-Cabo, B. Method for the Preparation of Nanoparticles in Ionic Liquids. Patent US20130221289A1, 29 August 2013.

57. Kim, S.W.; Chung, H.; Kwon, J.-H.; Yoon, H.G.; Kim, W. Facile Synthesis of Silver Chloride Nanocubes and Their Derivatives. Bull. Korean Chem. Soc. 2010, 31, 2918-2922. [CrossRef]

58. Song, J.; Roh, J.; Lee, I.; Jang, J. Low temperature aqueous phase synthesis of silver/silver chloride plasmonic nanoparticles as visible light photocatalysts. Dalton Trans. 2013, 42, 13897-13904. [CrossRef] [PubMed]

59. Husein, M.M.; Rodil, E.; Vera, J.H. A novel method for the preparation of silver chloride nanoparticles starting from their solid powder using microemulsions. J. Colloid Interface Sci. 2005, 288, 457-467. [CrossRef]

60. Petit, C.; Lixon, P.; Pileni, M.P. In situ synthesis of silver nanocluster in AOT reverse micelles. J. Phys. Chem. 1993, 97, 12974-12983. [CrossRef]

61. Choi, M.; Shin, K.H.; Jang, J. Plasmonic photocatalyticsystem using silver chloride/silver nanostructures under visible light. J. Colloid Interface Sci. 2010, 341, 83-87. [CrossRef] [PubMed]

62. Wang, W.; Lu, W.; Jiang, L. AgCl and Ag/ $\mathrm{AgCl}$ hollow spheres based on self-assemblies of a multi-amine head surfactant. J. Colloid Interface Sci. 2009, 338, 270-275. [CrossRef] [PubMed]

63. Zhang, H.; Wang, G.; Chen, D.; Lv, X.; Li, J. Tuning photoelectrochemical performances of Ag@TiO $\mathrm{O}_{2}$ nanocomposites via reduction/oxidation of Ag. Chem. Mater. 2008, 20, 6543-6549. [CrossRef]

64. Ma, J.; Guo, S.; Guo, X.; Ge, H. A mild synthetic route to $\mathrm{Fe}_{3} \mathrm{O}_{4} @ \mathrm{TiO}_{2}-\mathrm{Au}$ composites: Preparation, characterization and photocatalytic activity. Appl. Surf. Sci. 2015, 353, 1117-1125. [CrossRef]

65. Torres, J.D.; Faria, E.A.; Souza, J.R.; Prado, A.G. Preparation of photoactive chitosan-niobium (V) oxide composites for dye degradation. J. Photochem. Photobiol. A Chem. 2006, 182, 202-206. [CrossRef]

66. Prado, A.G.; Bolzon, L.B.; Pedroso, C.P.; Moura, A.O.; Costa, L.L. Nb2O5 as efficient and recyclable photocatalyst for indigo carmine degradation. Appl. Catal. B Environ. 2008, 82, 219-224. [CrossRef]

67. Bhatia, V.; Malekshoar, G.; Dhir, A.; Ray, A.K. Enhanced photocatalytic degradation of atenolol using graphene $\mathrm{TiO}_{2}$ composite. J. Photochem. Photobiol. A Chem. 2017, 332, 182-187. [CrossRef]

68. Li, F.; Kang, Y.; Chen, M.; Liu, G.; Lv, W.; Yao, K.; Chen, P.; Huang, H. Photocatalytic degradation and removal mechanism of ibuprofen via monoclinic $\mathrm{BiVO}_{4}$ under simulated solar light. Chemosphere 2016, 150, 139-144. [CrossRef] [PubMed]

69. Rodil, R.; Quintana, J.B.; Cela, R. Transformation of phenazone-type drugs during chlorination. Water Res. 2012, 46, 2457-2468. [CrossRef] [PubMed]

70. Rodil, R.; Quintana, J.B.; Cela, R. Reaction of $\beta$-blockers and $\beta$-agonist pharmaceuticals with aqueous chlorine. Investigation of kinetics and by-products by liquid chromatography quadrupole time-of-flight mass spectrometry. Anal. Bioanal. Chem. 2012, 403, 2385-2395.

71. Salgado, R.; Pereira, V.; Carvalho, G.; Soeiro, R.; Gaffney, V.; Almeida, C.; Cardoso, V.V.; Ferreira, E.; Benoliel, M.; Ternes, T.; et al. Photodegradation kinetics and transformation products of ketoprofen, diclofenac and atenolol in pure water and treated wastewater. J. Hazard. Mater. 2013, 244, 516-527. [CrossRef]

72. Zeng, C.; Ji, Y.; Zhou, L.; Zhang, Y.; Yang, X. The role of dissolved organic matters in the aquatic photodegradation of atenolol. J. Hazard. Mater. 2012, 239, 340-347. [CrossRef]

73. Yang, H.; Ao, Z.; Li, G.; Song, W.; Cooper, W.J.; Luo, H.; Guo, X. Photocatalytic degradation kinetics and mechanism of environmental pharmaceuticals in aqueous suspension of $\mathrm{TiO}_{2}$ : A case of $\beta$-blockers. J. Hazard. Mater. 2010, 179, 834-839. [CrossRef] [PubMed] 